\title{
Tuberculosis treatment outcomes among prisoners and general population in Zomba, Malawi
}

\author{
Victor Singano ${ }^{1,2^{*}}$ (D) Esther Kip ${ }^{1,3}$, Wilson Ching'ani ${ }^{4}$ and Lawrence Chiwaula ${ }^{5}$
}

\begin{abstract}
Background: TB remains a major global health problem. It is particularly prevalent in prisons in sub-Saharan Africa due to overcrowding, malnutrition, high HIV prevalence and insufficient medical services. Prisoners have experienced worse TB treatment outcomes than the general population. The researchers investigated the TB treatment outcomes and predictors of unsuccessful treatment outcomesamong prisoners and the general population in Zomba, Malawi.
\end{abstract}

Methods: We retrospectively reviewed TB registers of prisoners and the general population diagnosed with TB from January 2011 to December 2016 at Zomba Maximum Central Prison and Zomba Central Hospital, Malawi. The study used routinely collected data extracted from national, standardized TB treatment monitoring tools. Successful treatment outcome was classified as the total for cured and completed treatment while unsuccessful treatment outcome was classified as the total of deaths and treatment failures. We used descriptive statistics to compare the demographics and TB treatment parameters among prisoners and non - prisoners and computed multivariate analysis to predict the independent factors of unsuccessful treatment outcomes.

Results: Of 1652 registered cases, 27\% were prisoners (all males) and 72\% were non-prisoners (58\% males). The median age was 35 years (IQR: 29-42); 76\% were Pulmonary TB cases (78\% among prisoners vs 75\% among general population); $83 \%$ were new TB cases (77\% among prisoners vs $86 \%$ among general population); and 65\% were HIV positive (50\% among prisoners vs $71 \%$ among general population). Regarding treatment outcome, 1472 (89\%) were cured and/or completed treatment (93\% among prisoners vs $88 \%$ among general population), $2(0.2 \%)$ were treatment failures, 122 (8\%) died (5\% among prisoners vs $8 \%$ among general population) and 55 (3\%) were not evaluated (1\% among prisoners vs $4 \%$ among general population). Unsuccessful TB treatment outcomes were associated with age greater than 35 years ( $\mathrm{aOR}=0.68$ : 95\% C.I: 0.58-0.80), Extra-Pulmonary TB (aOR=1.69: 95\% C.l: 1.08-2.63) andHIV positive status (aOR $=0.63: 95 \%$ C.I: 0.42-0.94).

Conclusion: Maximum prisons provide a stable population that can be easily monitored throughout the course of TB treatment. Good TB treatment outcomes which are comparable to the general population can be achieved among Malawian prisoners despite the challenging prison conditions.

Keywords: Tuberculosis, Treatment outcome, Prisoners, General population

\footnotetext{
*Correspondence: vsingano@gmail.com

'Dignitas International, Zomba, Malawi

${ }^{2}$ Mothers2Mothers, Lilongwe, Malawi

Full list of author information is available at the end of the article
}

C C The Author(s). 2020 Open Access This article is licensed under a Creative Commons Attribution 4.0 International License, which permits use, sharing, adaptation, distribution and reproduction in any medium or format, as long as you give appropriate credit to the original author(s) and the source, provide a link to the Creative Commons licence, and indicate if changes were made. The images or other third party material in this article are included in the article's Creative Commons. licence, unless indicated otherwise in a credit line to the material. If material is not included in the article's Creative Commons licence and your intended use is not permitted by statutory regulation or exceeds the permitted use, you will need to obtain permission directly from the copyright holder. To view a copy of this licence, visit http://creativecommons.org/licenses/by/4.0/ The Creative Commons Public Domain Dedication waiver (http://creativecommons.org/publicdomain/zero/1.0/) applies to the data made available in this article, unless otherwise stated in a credit line to the data. 


\section{Background}

Tuberculosis (TB) remains a major global health problem. Globally in 2018, there were an estimated 10 million new $\mathrm{TB}$ cases of which $8.6 \%$ were among People living with HIV [1]. There were an estimated 1.4 million TB deaths worldwide with $17 \%$ ( 0.2 million deaths) resulting from $\mathrm{TB}$ disease among people living with HIV [1]. TB is the most common severe opportunistic infection associated with HIV in many resource-limited countries [2] with $68 \%$ of incident TB cases reported in the World Health Organization (WHO) South East Asia and African Regions [1]. TB is more common in prison populations than in the general populations [2] and HIV epidemic, poor living conditions, low socioeconomic status and poor general health, appears to have contributed directly to higher rates of TB within prisons [2]. Prisons therefore serve as reservoirs for TB infection, not only for inmates and staff but also for the general population as visitors come and go and released prisoners return to society [2]. A systematic review showed that 8.5 and $6.3 \%$ of $\mathrm{TB}$ in the general population in highand middle/low income countries, respectively, was attributed to the TB in prisons [3].

In 2018, Malawi reported an estimated 15,000 TB case notifications (181 cases per 100,000 population) with a $48 \%$ HIV/TB co-infection rate $(99 \%$ on ART anti-retroviral therapy $\}$ ) and $86 \% \mathrm{~TB}$ treatment success rate [1]. Malawi is one of the focus countries in the End TB Strategy era (2016-2035), as it is in the top 30 countries of high TB incidence among people living with HIV [1].

Data from the WHO epidemiological surveillance for TB treatment outcomes of 2017 cohort showed TSR of $76 \%$ in the WHO Region of the Americas(due to high levels of loss to follow up and missing data), $78 \%$ in the European Region (due to high rates of treatment failure and deaths, from high rates of MDR-TB),; 83\% in South East Asia; and82\% in sub - Saharan Africa [1]. In contrast, Prison settings have shown sub-optimal TB treatment success rates than the recommended $90 \%$ set by the End TB Strategy. TB treatment outcomes' studies among prisoners showed TSR of 50, 45, 48\% in Brazil(2011) [4], South Africa(2009) [5] and Uganda(2012, [6]), respectively. The poor TB TSR in prisons might compromise TB control and contribute to the development of Multi Drug Resistant Tuberculosis (MDR-TB), currently at a rate 7.7 per 100,000 population in the WHO African Region [1]. In Malawi (2014), the prevalence of MDR-TB was $0.4 \%$ among new cases and $4.8 \%$ among retreatment cases [7].

Standard TB treatment outcomesare known to be influenced by a number of factors including HIV coinfection, but the evidence on factors that are most influential for prisoners,is not known [2]..
While some studies found lower TB treatment success rates among TB/HIV patients [8-10], other reported comparable rates to those infected only with TB [11]. Since 2011 Dignitas International (DI) in conjunction with the Ministry of Health has been providing integrated HIV/TB services to Zomba Central Hospital and Zomba Central Prison in Zomba, Malawi. The Zomba Central Prison is overcrowded (houses approximately 2500 prisoners at any point in time for a facility meant for 800 prisoners). Despite the evidence on the higher $\mathrm{TB}$ cases in prisons than the general population, TB TSR are not disaggregated according to prisonsTB TSR serves as a proxy for the quality of TB control as a secondary prevention. Therefore,we investigated the TB treatment outcomes and predictors of unsuccessful treatment outcomes among prisoners and non - prisoners to audit the effectiveness of TB control in identifying gaps in the national treatment policy and practice in prisons to initiate evidence based practice. .

\section{Methods \\ Study design and setting}

A retrospective cross-sectional study was conducted at the Zomba Central Prison (ZCP) and Zomba Central Hospital (ZCH), Malawi. The sites were purposefully selected. Zomba Central Prison is the maximum security prison with the highest prison population in Malawi. On average, it houses approximately 2500 prisoners in a facility meant for 800 prisoners. Zomba Central Hospital is a tertiary semi - urban referral hospital (catchment area 3.1 million) for the South East Health Zone in Zomba, Malawi.

The data source was the National TB register where relevant clinical information for all patients diagnosed with active TB disease are monitored throughout the course of their treatment.

\section{Organization of Health and TB services in Malawi}

Malawi follows a three tier health care system which is connected by a patient referral system. Primary care where the bulk of health care occurs consists of hospitals that provide out-patient services, holding wards and community based outreach services. Secondary level care is provided by district hospitals in 28 districts which provide the same basic services as the primary care facilities in addition to a few more, such as: radiology, ambulance, operating theatre and basic laboratory. The central hospitals (located in 4 urban areas) provide tertiary specialized services.

There is decentralized provision of TB and HIV services. TB diagnostic services include smear microscopy (widely available in primary care facilities) and GeneXpert MTB/RIF (district and central hospitals) on spot and morning sputum samples. The National TB 
Reference Laboratory provides high level diagnostic services, including solid and liquid culture and drug sensitivity testing. It is also responsible for quality assurance services to the peripheral laboratories (central and district hospitals). TB treatment follows Direct Observed Treatment Strategy (DOTS).

Malawi prisons are categorized into high and low facilities. The high volume facilities (central prisons) have onsite clinics that provide primary care services and basic TB diagnostic services (smear microscopy and gene-expert). Low volume prisons do not have onsite clinics but depends on referring patients to the nearest primary or secondary care facility. In the central prisons, prisoners are symptomatically screened for TB, Sexually Transmitted Infections (STIs) and HIV during their entry, stay and exit by prison wardens. Prisoners with cough submit spot and morning samples which are analyzed using either smear microscopy or GeneXpert MTB/RIF at the prison laboratory (current Malawi TB program guidelines require GeneXpert MTB/RIF as first test for sputum from prisoners). Prisoners suspected of smear-negative PTB or extra-pulmonary TB (ЕPTB) are referred to the nearest district or central hospital for further investigations. Dignitas International provided clinical officers and nurses to support direct service delivery in the prison clinic (due to the shortage of health workers in the prison), and trained and supervised the prison wardens in DOTS.

TB services data is captured on paper based registers: chronic cough register for presumptive TB cases, district $\mathrm{TB}$ register for active $\mathrm{TB}$ cases and $\mathrm{TB}$ patient cards for individual monitoring of $\mathrm{TB}$ treatment (Table 1). The central prisons have their own $\mathrm{TB}$ treatment registers (same as the district TB registers). All prisoners diagnosed with TB are also captured in the district TB treatment register so that the district can keep track of the prisoners. Data is collected on a quarterly basis by the National TB program through an integrated HIV/TB program supervision.

\section{Study participants}

All prisoners and the general population aged 15 years and above who were diagnosed and put on TB treatment at the Zomba Central Prison and Zomba Central Hospital from January 2011 to December 2016 were included (Fig. 1).

\section{Ethical consideration}

Ethical approval was obtained from the College of Medicine Research Ethics Committee (COMREC Reference No: P.05/18/2394). Individual informed consent was not sought since the study used fully anonymized retrospective data. Prior written authorization was obtained from Zomba Central Hospital, Zomba District Health Office and Malawi Prison Services.

\section{Data collection, management and analysis}

We used routinely collected data extracted anonymously from the national standardized monitoring tools in ZCP and $\mathrm{ZCH}$ : TB register (age, sex, occupation, site of disease, history of previous treatment, type of diagnosis, treatment outcome, HIV test status, Anti -Retroviral Therapy $\{\mathrm{ART}\}$ and Cotrimoxazole Prophylactic Treatment $\{\mathrm{CPT}\}$ status). The data was collected in an anonymized way, entered into a data extraction sheet and then into the Access database then analyzed by STATA 13. Descriptive analysis was used to determine the patient characteristics and treatment outcomes. Chi squared tests were used to compare the characteristics between the prisoners and the general population. Bivariate logistic regression was used to assess associations between patient characteristics and poor treatment outcomes. The risk factors for poor TB treatment outcomes were analyzed using multivariate analyses adjusted for potential confounders. Odd ratios were provided with 95\% confidence intervals and $p$-values (using a statistical significance level of $<0.05$ ).

Table 1 Operational definitions of TB treatment outcomes

\begin{tabular}{|c|c|}
\hline Cured & $\begin{array}{l}\text { A pulmonary TB patient with bacteriologically confirmed TB at the beginning of treatment who was smear- or culture-negative } \\
\text { in the last month of treatment and on at least one previous occasion. }\end{array}$ \\
\hline $\begin{array}{l}\text { Treatment } \\
\text { completed }\end{array}$ & $\begin{array}{l}\text { A TB patient who completed treatment without evidence of failure but with no record to show that sputum smear or culture } \\
\text { results in the last month of treatment and on at least one previous occasion were negative, because tests were not done or } \\
\text { because results are unavailable. }\end{array}$ \\
\hline Treatment success & Sum of cured and treatment completed. \\
\hline Treatment failed & TB patient whose sputum smear or culture is positive at month 5 or later during treatment. \\
\hline Died & TB patient who dies for any reason before starting or during the course of treatment. \\
\hline Loss To Follow Up & TB patient who did not start treatment or whose treatment was interrupted for 2 consecutive months or more. \\
\hline Not Evaluated & $\begin{array}{l}\text { TB patient for whom no treatment outcome is assigned. This includes cases "transferred out" to another treatment unit as well } \\
\text { as cases for whom the treatment outcome is unknown to the reporting unit. }\end{array}$ \\
\hline
\end{tabular}




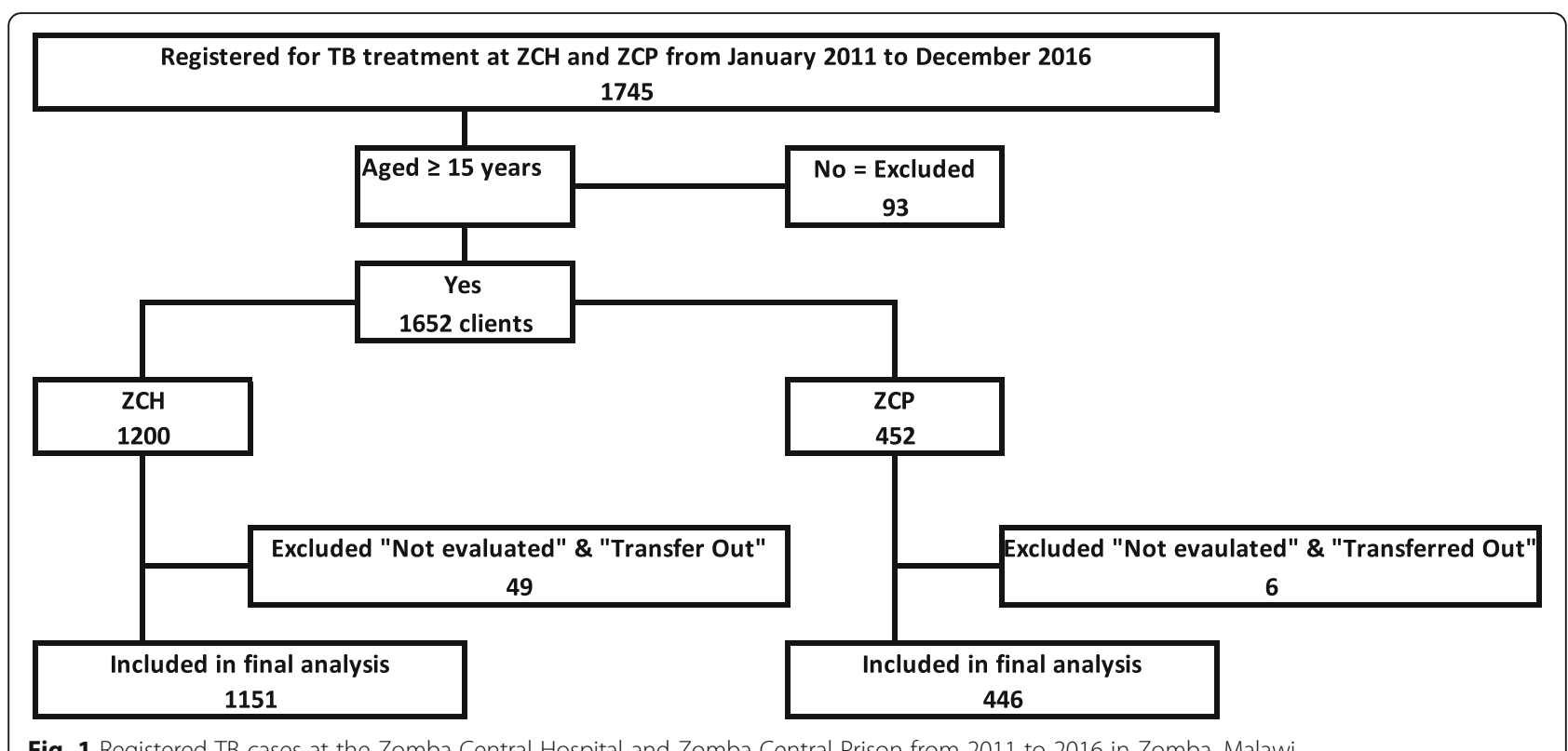

Fig. 1 Registered TB cases at the Zomba Central Hospital and Zomba Central Prison from 2011 to 2016 in Zomba, Malawi

\section{Results}

\section{Socio-demographic and clinical characteristics of the} patients

Table 2 shows the baseline characteristics of the 1652 registered adult TB patients. Twenty seven percent (27\%) were prisoners (all males) and 72\% representeda general population (58\% males). The median age was 35 years (IQR: 29-42); 76\% were Pulmonary TB cases (78\% among prisoners vs $75 \%$ among general population); $83 \%$ were new TB cases (77\% among prisoners vs $86 \%$ among general population); and 65\% were HIV positive $(50 \%$ among prisoners vs $71 \%$ among general population).

\section{Trends in TB registrations and treatment outcomes}

Overall all forms of TB were gradually decreasing among the prisoners from 2011 to 2013, and the trend increased from 2014 to 2016 while in the general population, all forms of TB peaked in 2012 and gradually declined from 2013 to 2016.There is a significant difference in the trend of all forms of TB among prisoners and the general population $\left(\mathrm{X}^{2}\right.$ trend $\left.=26.1: P<0.05\right)$.

Among the prisoners, the PTB cases plateaued from 2011 to 2015, and thetrend increased in 2016 while among the general population, the PTB cases peaked in 2012 and gradually declined from 2013 to 2016. ЕРТВ cases in the two populations remained stable over the 6 year period (Fig. 2). There was a difference in the treatment outcomes among the two populations $\left(\mathrm{X}^{2}=33.2\right.$; $\mathrm{P}<0.05)$. Overall, the mean TSR was $93 \%$ among prisoners and $88 \%$ in thegeneral population), $2(0.2 \%)$ were treatment failures (general population), $122(8 \%)$ died (5\% among prisoners vs $8 \%$ among general population) and $55(3 \%)$ were not evaluated (1\% among prisoners vs $4 \%$ among general population). In the general population, the trend for the TSR declined in 2012 and gradually increased from 2013 to 2016 while it remained fairly constant among the prisoners over the study period (Fig. 3 and Table 2).

Factors associated with unsuccessful treatment outcomes Multivariate logistic regression showed that age greater than 35 years $(\mathrm{aOR}=0.68: 95 \%$ C.I: $0.58-0.80)$, ExtraPulmonary TB (aOR $=1.69: 95 \%$ C.I: $1.08-2.63)$ and HIV positive status $(\mathrm{aOR}=0.63$ : $95 \%$ C.I: $0.42-0.94)$ were the factors associated with unsuccessful TB treatment outcomes (Table 3).

\section{Discussion}

In this 6 year retrospective study, the results show differences in the trend of all forms of TB and TB treatment success rates among the prisoners and the general population. Age greater than 35 years, HIV positive status and extra - Pulmonary TB were independently associated with unsuccessful TB treatment outcomes (death and treatment failure). In addition, it was found that the prison only registered male TB patients over the course of the 6 years.

There was an increase in the TB cases at the Zomba Central Prison from 2014 to2016 due to the introduction of the TB mass screening campaigns using a mobile $\mathrm{X}$ ray machine while at the Zomba Central Hospital, the TB cases peaked in 2012 and thereafter there was a steady decline from 2013 to 2016 . This might be attributed to the further scale up of antiretroviral therapy 
Table 2 Socio-demographic and clinical characteristics of the patients

\begin{tabular}{|c|c|c|c|}
\hline Characteristic & $\begin{array}{l}\text { Total } \\
\text { n (\%) }\end{array}$ & Zomba Central Hospital, n (\%) & Zomba Central Prison, n (\%) \\
\hline Total participants & 1652 & $1200(72.6)$ & $452(27.4)$ \\
\hline \multicolumn{4}{|l|}{$\operatorname{Sex}(N=1651)$} \\
\hline Male & $1148(69.5)$ & $697(58.0)$ & $451(100.0)$ \\
\hline Female & $503(30.5)$ & $503(42.0)$ & $0(0)$ \\
\hline \multicolumn{4}{|l|}{$\operatorname{Age}(N=1648)$} \\
\hline Median (IQR) & $35(29.4)$ & & \\
\hline $15-24$ & $196(11.9)$ & $138(11.5)$ & $58(12.8)$ \\
\hline $25-34$ & $626(38.0)$ & $424(35.3)$ & $202(44.7)$ \\
\hline $35-44$ & $488(29.6)$ & $350(29.2)$ & $138(30.5)$ \\
\hline $45-54$ & $176(10.7)$ & $141(12.0)$ & $35(8 . .0)$ \\
\hline$=>55$ & $162(9.8)$ & $145(12.1)$ & $17(4.0)$ \\
\hline \multicolumn{4}{|l|}{ TB Registration Year $(N=1652)$} \\
\hline 2011 & $286(17.1)$ & $212(17.7)$ & $74(16.3)$ \\
\hline 2012 & $302(18.3)$ & $246(20.5)$ & $56(12.4)$ \\
\hline 2013 & $250(15.1)$ & $201(16.8)$ & $49(10.8)$ \\
\hline 2014 & $270(16.3)$ & $193(16.1)$ & $77(17.4)$ \\
\hline 2015 & $255(15.4)$ & $178(14.8)$ & $77(17.4)$ \\
\hline 2016 & $289(17.5)$ & $170(14.1)$ & $119(26.3)$ \\
\hline \multicolumn{4}{|l|}{$T B \operatorname{Form}(N=1652)$} \\
\hline Pulmonary TB (bacteriologically, clinically) & $1257(76.1)$ & $904(75.3)$ & $353(78.1)$ \\
\hline Extra-Pulmonary TB & $395(23.9)$ & $296(24.7)$ & 99 (21.9) \\
\hline \multicolumn{4}{|l|}{ TB Category $(N=1652)$} \\
\hline New & $1376(83.3)$ & $1027(85.5)$ & $349(77.2)$ \\
\hline Relapse & $79(4.8)$ & $46(3.8)$ & $33(7.3)$ \\
\hline Return After Loss To Follow Up & $4(0.2)$ & $4(0.3)$ & $0(0)$ \\
\hline Failed & $1(0.1)$ & $1(0.1)$ & $0(0)$ \\
\hline Other & $191(11.6)$ & $122(10.2)$ & $70(15.5)$ \\
\hline \multicolumn{4}{|l|}{ HIV Status $(N=1652)$} \\
\hline Positive & $1080(65.4)$ & $853(71.1)$ & $227(50.2)$ \\
\hline Negative & $530(32.1)$ & $319(26.6)$ & $211(46.7)$ \\
\hline Unknown & $42(2.5)$ & $28(2.3)$ & $14(3.1)$ \\
\hline \multicolumn{4}{|l|}{ TB treatment outcomes $(N=1652)$} \\
\hline Cured & $479(29.0)$ & $308(25.6)$ & $171(37.8)$ \\
\hline Treatment Completed & $993(60.1)$ & $743(61.9)$ & $250(55.3)$ \\
\hline Treatment Failed & $2(0.2)$ & $2(0.2)$ & $0(0)$ \\
\hline Died & $122(8.1)$ & $97(8.0)$ & $25(5.5)$ \\
\hline Transferred Out & $12(0.7)$ & $12(1.0)$ & $0(0)$ \\
\hline Not Evaluated & $43(2.6)$ & $37(3.1)$ & $6(1.3)$ \\
\hline
\end{tabular}

*The percentage in the 5 year trend section is provided as a percentage of the total number over 6 years

program through the Option B plus which was rolled out in 2011 in Malawi [12].

There were differences in the mean TB TSR among the two study populations (93\% among prisoners and $88 \%$ among the general population. However, the $89 \%$ overall TB treatment Success Rate (TSR) is comparable to other studies done in resource limited settings and it is within reach of the End TB Strategy target of $=>90 \%$. Similar studies conducted in the general population (from 2008 to 2010) at a Large District Hospital [8] and 


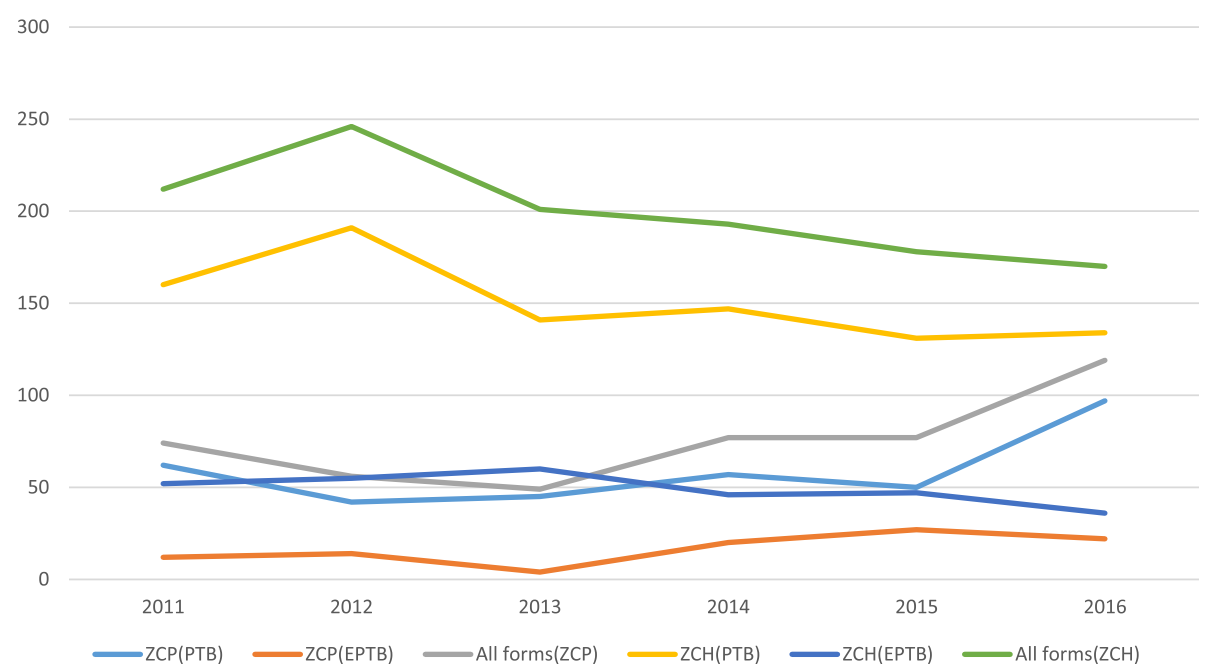

Fig. 2 Trend of all forms registered TB cases at Zomba Central Prison and Zomba Central Hospital in Malawi. There is a significant difference in the trend of all forms of TB among the prisoners and the general population $\left(X^{2}=26.1 ; P<0.05\right)$

a Central Hospital [13] in Malawi and Ethiopia showed an $86 \%$ TSR ([14]. This is also higher than the 73\% TSR [15] from 27 prisons in Malawi in 2007, 66\% TSR reported in Zambian prison [16] in 2010-2011 and 48\% TSR in Ugandan prisons [6] from 2011 to 2012. However, the TSR is comparable to recent studies done in prisons in sectionEthiopia [17] $(89,90 \%)$ but slightly lower than the study done in South Africa [5] (92\%) and Ethiopia [17] (94\%). The higher TSR in prison than the general population might be attributed to the maximum security prisons where the prisoners incarcerated for a longer sentences are bound to be within the prison and within reach of the wardens for the DOTS [16]. The varied intra prison differences may be due to the high turnover of prisoners andremandees (they are not yet sentenced and can be transferred out to another facility or released into the general public where they are lost to follow up) [16]. There can be poor linkage within prison facilities and the communities as once prisoners are released into the community, they are not adequately actively followed up for continuity of treatment $[18,19]$.

This studyshowed an overall $2.6 \%$ loss to follow-up which was lower than in other studies reported in

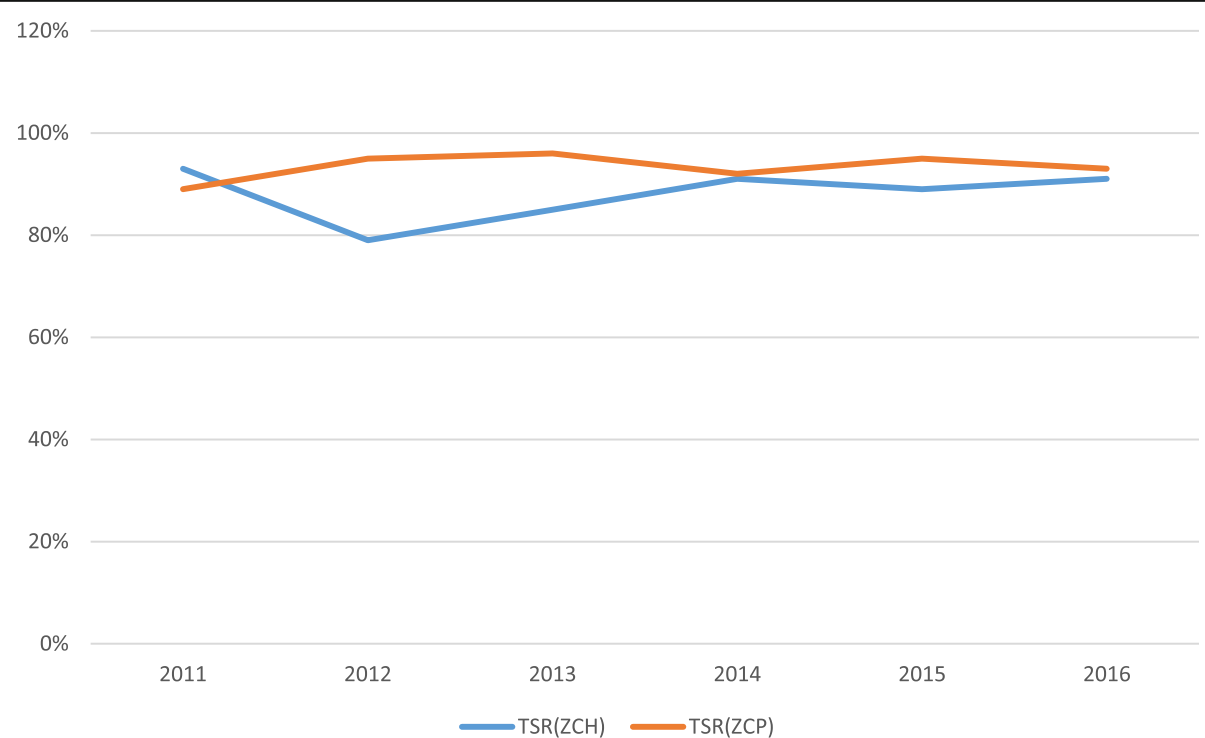

Fig. 3 Trend of TB treatment success rates (TSR) among prisoners at Zomba Central Prison (ZCP) and the general population at Zomba Central Hospital $(\mathrm{ZCH})$ in Malawi. There is a significant difference in the trend of all forms of TB among the prisoners and the general population $\left(X^{2}=33.2 ; P<0.05\right)$ 
Table 3 Factors associated with unsuccessful treatment outcomes (death and treatment failure), $n=1597$

\begin{tabular}{|c|c|c|c|c|c|c|c|}
\hline Variable & Total (\%) & $\begin{array}{l}\text { Treatment } \\
\text { Success }\end{array}$ & $\begin{array}{l}\text { Unsuccessful } \\
\text { Treatment }\end{array}$ & $\begin{array}{l}\text { Crude OR } \\
(95 \% \mathrm{Cl})\end{array}$ & $\begin{array}{l}\mathrm{P} \text { - } \\
\text { value }\end{array}$ & $\begin{array}{l}\text { Adjusted OR } \\
(95 \% \mathrm{Cl})\end{array}$ & $\begin{array}{l}\text { P- } \\
\text { value }\end{array}$ \\
\hline \multicolumn{8}{|l|}{ Sex } \\
\hline Female & $486(30.5)$ & $444(91.4)$ & $42(8.6)$ & 1 & & & \\
\hline Male & $\begin{array}{l}1110 \\
(69.5)\end{array}$ & $1027(92.5)$ & $83(7.5)$ & $1.17(0.79-1.72)$ & 0.43 & & \\
\hline Age & & & & & & $0.68(0.58-0.80)$ & 0.00 \\
\hline $15-24$ & $186(11.7)$ & $180(96.8)$ & $6(3.2)$ & 1 & & & \\
\hline $25-34$ & $606(38.0)$ & $566(93.4)$ & $40(6.6)$ & $0.47(0.20-1.13)$ & 0.09 & & \\
\hline $35-44$ & $472(29.6)$ & $436(92.4)$ & $36(7.6)$ & $\begin{array}{l}0.40(0.17- \\
0.97)\end{array}$ & 0.04 & & \\
\hline $45-54$ & $172(10.8)$ & $156(90.7)$ & $16(9.3)$ & $\begin{array}{l}0.32(0.12- \\
0.85)\end{array}$ & 0.02 & & \\
\hline$=>55$ & $157(9.9)$ & $130(82.8)$ & $27(17.2)$ & $\begin{array}{l}0.16(0.06- \\
0.40)\end{array}$ & 0.00 & & \\
\hline Facility & & & & & & $1.06(0.62-1.79)$ & 0.82 \\
\hline Zomba Central Prison & $446(27.9)$ & $421(94.4)$ & $25(5.6)$ & 1 & & & \\
\hline Zomba Central Hospital & $\begin{array}{l}1151 \\
(72.1)\end{array}$ & $1051(91.3)$ & $100(8.7)$ & $\begin{array}{l}1.60(1.01- \\
2.51)\end{array}$ & 0.04 & & \\
\hline TB Registration Year & & & & & & $0.92(0.52-1.38)$ & 0.98 \\
\hline 2011 & $279(17.5)$ & $263(94.3)$ & $16(5.7)$ & 1 & & & \\
\hline 2012 & $276(17.3)$ & $247(89.5)$ & $29(10.5)$ & $0.53(0.27-1.03)$ & 0.06 & & \\
\hline 2013 & $241(15.1)$ & $217(90.0)$ & $24(10.0)$ & $0.51(0.26-1.00)$ & 0.05 & & \\
\hline 2014 & $269(16.8)$ & $247(90.2)$ & $22(8.2)$ & $0.66(0.33-1.30)$ & 0.23 & & \\
\hline 2015 & $249(15.6)$ & $232(93.2)$ & $17(6.8)$ & $0.90(0.43-1.88)$ & 0.78 & & \\
\hline 2016 & $283(17.7)$ & $266(94.0)$ & $17(6.0)$ & $0.91(0.44-1.86)$ & 0.79 & & \\
\hline TB Form & & & & & & $1.69(1.08-2.63)$ & 0.01 \\
\hline Pulmonary TB & $\begin{array}{l}1214 \\
(76.0)\end{array}$ & $1130(93.1)$ & $84(6.9)$ & 1 & & & \\
\hline Extra-Pulmonary TB & $383(24.0)$ & $342(89.3)$ & $41(10.7)$ & $\begin{array}{l}1.61(1.08- \\
2.38)\end{array}$ & 0.02 & & \\
\hline TB Category & & & & & & $0.97(0.67-1.40)$ & 0.88 \\
\hline New & $\begin{array}{l}1332 \\
(83.4)\end{array}$ & $1233(92.6)$ & $99(7.4)$ & 1 & & & \\
\hline $\begin{array}{l}\text { Relapse/ Return After Loss To Follow Up/ } \\
\text { Failed }\end{array}$ & $78(4.9)$ & $76(97.4)$ & $2(2.6)$ & $\begin{array}{l}3.04(0.73- \\
12.59)\end{array}$ & 0.12 & & \\
\hline Other & $186(11.7)$ & $162(87.0)$ & $24(13.0)$ & $\begin{array}{l}0.54(0.33-0 \\
.87)\end{array}$ & 0.01 & & \\
\hline HIV Status & & & & & & $0.63(0.42-0.94)$ & 0.02 \\
\hline Negative & $518(32.4)$ & $497(96.0)$ & $21(4.0)$ & 1 & & & \\
\hline Positive & $\begin{array}{l}1042 \\
(65.3)\end{array}$ & $944(90.6)$ & $98(9.4)$ & $\begin{array}{l}0.40(0.25- \\
0.66)\end{array}$ & 0.00 & & \\
\hline
\end{tabular}

similar limited resource setting in prisons in Uganda (43.0\%) [6], and Brazil (13.0\%) [4]. The lower rate of loss to follow up is attributed to the stable prison population at the Zomba Central Prison that is serving long term sentences hence not easily transferred or released [16].

The 5.5\% death rate is comparable to the death rate observed in Uganda prison [6] but higher than the 1.4\% death rate recorded in Ethiopia [17], 1.8\% death rate recorded in South Africa [5] and 2\% death rate recorded in Brazil [4]. This high death rate could be attributed to the poor prison living conditions -overcrowding [18], poor nutrition [19] and possibly to the rate of HIV/TB co-infection without use of antiviral therapy (due to the lower coverage of antiretroviral therapy use during this time period), which has been shown to be associated with unsuccessful treatment outcome $[8,20]$. This study 
also showed that unsuccessful TB treatment outcome was associated with age greater than 35 years old. Similar studies in Botswana and Nigeria have shown that older age may be confounded by the high risk behaviorse.g. alcohol and drug use which are common in prison settings and general population especially among men. This leads to poor adherence which result to poor treatment outcomes.

A common risk factor for unsuccessful TB treatment outcome, Extra Pulmonary TB was also found in this study. This might be due to the severe nature of the EPTB,delays in diagnosing EPTB [21] duelimited diagnostic capacity and lack of treatment monitoring tests for EPTB cases [22].

In this study, gender comparisons were not possible among prisoners and the general population because the prison registered male TB patients only in the whole study period. Similar studies globally have shown unevenly distributed high proportions of male prisoners than female prisoners $([19,23,24])$.Globally, there has been no universally accepted explanation to this disparity and most criminology studies point to the socialized gender roles and different expectationsof male and female behaviors [25].

The general findings from this study shows that prisoners can achieve good TB treatment outcomes which are comparable to the general population. The long serving prisoners in a maximum security prison provides an opportunity of uninterrupted treatment since they are not easily transferred out to other facilities. This calls for continued support to the prison health programs [26]. Several strategies can be combined to yield successful efforts in the fight against TB in the prison setting. TB mass screenings can be used to increase TBcase detection [24]. Since the TB treatment outcomes are worsened by HIV positive status $[5,8,20]$ scaling up of the 3 phase integrated screening and treatment for HIV, TB and nutrition during entry, stay and exit of prison could increase access to HIV, TB and Nutritional screening and subsequent linkage to appropriate treatment services.

The strengths of this study include the following that we used routine program based data that is collected from the facility national TB registers which are used for TB patient registration, monitoring and evaluation from within a national public system. We studied a large number of TB patients and the results are representative of the national TB TSR. The study adhered to STROBE (Strengthening the Reporting of Observational Studies in Epidemiology) guidelines for the reporting of observational data.

Some noted limitationsinclude the use of retrospective data in which other important risk factors for unsuccessful TB treatment outcomes were not assessed (smoking status, alcohol status, body mass index, disaggregation of EPTB and HIV, and TB drug side effects). The analysis also excluded patients who were transferred out and those not evaluated which might posed a bias.

\section{Conclusion}

Good TB treatment outcomes which are comparable to the general population were achieved among Malawian prisoners despite the challenging prison conditions due to the stable nature of the long serving prisoners in a maximum security prison who do not have TB treatment interruptions and health care workers' and technical assistance support from Dignitas International. This calls for continued support for prison health programs. Further longitudinal research is required to look at the other contributing factors in details.

\section{Abbreviations}

ART: Antiretroviral therapy; COMREC: College of Medicine Research Ethics Committee; CPT: Cotrimoxale prevention therapy; DI: Dignitas International; DOTS: Direct observed treatment strategy; EPTB: Extra pulmonary tuberculosis; MDR-TB: Multi-drug resistant tuberculosis; TSR: Treatment success rate; TB: Tuberculosis; WHO: World Health Organization; ZCH: Zomba Central Hospital; ZCP: Zomba Central Prison

\section{Acknowledgements}

We would like to thank patients and staff of the Zomba Central Hospital and Zomba Central Prison, Zomba District, Malawi.

\section{Authors' contributions}

VS and EK designed the study and analyzed the data. VS and EK wrote the first draft of the manuscript. LC and WC contributed to subsequent drafts and have reviewed and agreed with the content of the final manuscript. The author(s) read and approved the final manuscript.

\section{Funding}

Dignitas International's work at the Zomba Central Hospital and Zomba Central Prison was funded by USAID. USAID had no role in the study design, data collection, data analysis, decision to publish or preparation of the manuscript.

\section{Availability of data and materials}

The datasets used during the current study are available from the corresponding author on reasonable request.

\section{Ethics approval and consent to participate}

Ethical approval was obtained from The College of Medicine Research Ethics Committee (COMREC Reference No: P.05/18/2394). Individual informed consent was not sought since the study used fully anonymized retrospective data.

\section{Consent for publication}

Not applicable.

\section{Competing interests}

The authors declare that they have no conflict of interest.

\section{Author details}

'Dignitas International, Zomba, Malawi. ${ }^{2}$ Mothers2Mothers, Lilongwe, Malawi. ${ }^{3}$ Department of Mental Health, College of Medicine, Blantyre, Malawi.

${ }^{4}$ Zomba District Health Office, Zomba, Malawi. ${ }^{5}$ Prison Health Services, Zomba, Malawi. 
Received: 19 October 2019 Accepted: 4 May 2020

Published online: 15 May 2020

\section{References}

1. WORLD HEALTH ORGANIZATION. GLOBAL TUBERCULOSIS Report 2019. S.I.: WORLD HEALTH ORGANIZATION; 2019.

2. Telisinghe L, Charalambous S, Topp SM, Herce ME, Hoffmann CJ, Barron P, et al. HIV and tuberculosis in prisons in sub-Saharan Africa. Lancet Lond Engl. 2016;388(10050):1215-27.

3. Baussano I, Williams BG, Nunn P, Beggiato M, Fedeli U, Scano F. Tuberculosis Incidence in Prisons: A Systematic Review. PLoS Med 2010; 7(12). Available from: https://www.ncbi.nlm.nih.gov/pmc/articles/PMC3 006353/. [cited 2020 Apr 11].

4. Ribeiro Macedo L, Reis-Santos B, Riley LW, Maciel EL. Treatment outcomes of tuberculosis patients in Brazilian prisons: a polytomous regression analysis. Int J Tuberc Lung Dis Off J Int Union Tuberc Lung Dis. 2013;17(11): 1427-34.

5. Mnisi T, Tumbo J, Govender I. Factors associated with pulmonary tuberculosis outcomes among inmates in Potchefstroom prison in north west province. South Afr J Epidemiol Infect. 2013;28(2):96-101.

6. Schwitters A, Kaggwa M, Omiel P, Nagadya G, Kisa N, Dalal S. Tuberculosis incidence and treatment completion among Ugandan prison inmates. Int J Tuberc Lung Dis Off J Int Union Tuberc Lung Dis. 2014;18(7):781-6.

7. Abouyannis M, Dacombe R, Dambe I, Mpunga J, Faragher B, Gausi F, et al. Drug resistance of mycobacterium tuberculosis in Malawi: a cross-sectional survey. Bull World Health Organ. 2014;92(11):798-806.

8. Tweya H, Feldacker C, Phiri S, Ben-Smith A, Fenner L, Jahn A, et al. Comparison of treatment outcomes of new smear-positive pulmonary tuberculosis patients by HIV and antiretroviral status in a TB/HIV clinic, Malawi. Plos One. 2013;8(2):e56248.

9. Ali SA, Mavundla TR, Fantu R, Awoke T. Outcomes of TB treatment in HIV co-infected TB patients in Ethiopia: a cross-sectional analytic study. BMC Infect Dis. 2016;16(1):640.

10. Sinshaw Y, Alemu S, Fekadu A, Gizachew M. Successful TB treatment outcome and its associated factors among TB/HIV co-infected patients attending Gondar University referral hospital, Northwest Ethiopia: an institution based cross-sectional study. BMC Infect Dis. 2017:17(1):132.

11. Nglazi MD, Bekker L-G, Wood R, Kaplan R. The impact of HIV status and antiretroviral treatment on TB treatment outcomes of new tuberculosis patients attending co-located TB and ART services in South Africa: a retrospective cohort study. BMC Infect Dis 201515. Available from: https:// www.ncbi.n/m.nih.gov/pmc/articles/PMC4653912/. [cited 2018 Jan 4].

12. Kanyerere $H$, Harries AD, Tayler-Smith $K$, Jahn A, Zachariah $R$, Chimbwandira FM, et al. The rise and fall of tuberculosis in Malawi: associations with HIV infection and antiretroviral therapy. Tropical Med Int Health. 2016;21(1):1017.

13. Kanyerere HS, Mpunga J, Tweya H, Edginton M, Harries AD, Hinderaker SG, et al. Timing of antiretroviral therapy and effects on tuberculosis treatment outcomes in HIV-co-infected patients in Malawi. Public Health Action. 2012; 2(4):174-7.

14. Berhe G, Enquselassie F, Aseffa A. Treatment outcome of smear-positive pulmonary tuberculosis patients in Tigray region, Northern Ethiopia. BMC Public Health. 2012;12(1):537.

15. Kanyerere HS, Banda RP, Gausi F, Salaniponi FM, Harries AD, Mpunga J, et al. Surveillance of tuberculosis in Malawian prisons. Public Health Action. 2012; 2(1):10-4.

16. Hatwiinda S, Topp SM, Siyambango M, Harris JB, Maggard KR, Chileshe C, et al. Poor continuity of care for TB diagnosis and treatment in Zambian prisons: a situation analysis. Tropical Med Int Health. 2018;23(2):243-50.

17. Adane K, Spigt M, Dinant G-J. Tuberculosis treatment outcome and predictors in northern Ethiopian prisons: a five-year retrospective analysis. BMC Pulm Med. 2018;18(1):37.

18. Topp SM, Moonga CN, Luo N, Kaingu M, Chileshe C, Magwende G, et al. Mapping the Zambian prison health system: an analysis of key structural determinants. Glob Public Health. 2017;12(7):858-75.

19. Topp SM, Moonga CN, Luo N, Kaingu M, Chileshe C, Magwende G, et al. Exploring the drivers of health and healthcare access in Zambian prisons: a health systems approach. Health Policy Plan. 2016;31(9):1250-61.

20. Kayigamba FR, Bakker MI, Mugisha V, Naeyer LD, Gasana M, Cobelens F, et al. Adherence to tuberculosis treatment, sputum smear conversion and mortality: a retrospective cohort study in 48 Rwandan clinics. PLoS One 2013:8(9):e73501.

21. Asres A, Jerene D, Deressa W. Delays to treatment initiation is associated with tuberculosis treatment outcomes among patients on directly observed treatment short course in Southwest Ethiopia: a follow-up study. BMC Pulm Med. 2018;2:18 Available from: https://www.ncbi.nlm.nih.gov/pmc/articles/ PMC5930812/. [cited 2020 Jan 24].

22. Ejeta E, Beyene G, Balay G, Bonsa Z, Abebe G. Factors associated with unsuccessful treatment outcome in tuberculosis patients among refugees and their surrounding communities in Gambella regional state, Ethiopia. Plos One. 2018;13(10):e0205468.

23. Mitruka K, Volkmann T, Pratt RH, Kammerer JS. Disparities in tuberculosis treatment completion by incarceration status, U.S., 1999-2011. Am J Prev Med. 2017:52(4):483-90.

24. Morishita F, Garfin AMCG, Lew W, Oh KH, Yadav R-P, Reston JC, et al. Bringing state-of-the-art diagnostics to vulnerable populations: The use of a mobile screening unit in active case finding for tuberculosis in Palawan, the Philippines. PLoS One. 2017;12(2). Available from: https://www.ncbi.nlm.nih. gov/pmc/articles/PMC5289556/. [cited 2019 Oct 18].

25. Wehrman MM. Examining race and sex inequality in recidivism. Sociol Compass. 2011;5(3):179-89.

26. Dara M, Chadha SS, Melchers NV, van den Hombergh J, Gurbanova E, AlDarraji $\mathrm{H}$, et al. Time to act to prevent and control tuberculosis among inmates [official statement of the International Union against Tuberculosis and Lung Disease]. Int J Tuberc Lung Dis. 2013;17(1):4-5.

\section{Publisher's Note}

Springer Nature remains neutral with regard to jurisdictional claims in published maps and institutional affiliations.
Ready to submit your research? Choose BMC and benefit from:

- fast, convenient online submission

- thorough peer review by experienced researchers in your field

- rapid publication on acceptance

- support for research data, including large and complex data types

- gold Open Access which fosters wider collaboration and increased citations

- maximum visibility for your research: over $100 \mathrm{M}$ website views per year

At $\mathrm{BMC}$, research is always in progress.

Learn more biomedcentral.com/submissions 